\title{
Newly found arsons ignite the fire of gut CVHD
}

\author{
Defu Zeng
}

Diabetes and Metabolism Research Institute and Hematologic Malignancies and Stem Cell Transplantation Institute, The Beckman Research Institute of City of Hope, Duarte, California, USA.

\begin{abstract}
Acute graft-versus-host disease (CVHD) in the gut is common following hematopoetic cell transplantation (HCT) and is associated with high mortality. However, it remains unclear whether Th1 or Th17 CD4+ $\mathrm{T}$ cells can initiate acute gut GVHD. In this issue of the JCI, Ullrich and colleagues identified a subset of CD4+ $T$ cells that express high levels of IL-7R $\alpha$ and granulocyte-macrophage CSF (IL-7R $\alpha^{\text {hi }} \mathrm{CM}-\mathrm{CSF}^{+}$) cells that are involved in the induction of acute gut GVHD in murine models. The IL-7Ra $\alpha^{\text {hiCM- }}$ $\mathrm{CSF}^{+}$effector memory cells were BATF dependent, ROR $\gamma$ t independent, produced large amounts of CM-CSF and IFN- $\gamma$, and released little IL-17. CD4+IL-7R $\alpha^{\text {hi }}$ CM-CSF+ cells were not classical Th17 cells but had more of a Th1-like phenotype, despite their dependence on BATF. This work suggests that targeting the IL-7R/BATF/CM-CSF axis has therapeutic potential for treating acute gut CVHD.
\end{abstract}

chronic GVHD (11). Th17 cells mediate cutaneous chronic GVHD via IL-22 production (12); therefore, tissue infiltration of Th subsets is target-organ specific and inflammation-phase dependent. Gut tissue-infiltrating Th cells during the early acute phase of GVHD are predominantly IFN- $\gamma$-producing Th1 and Tc1 cells.

\section{IFN- $\gamma$ - but not IL-17-producing $\mathrm{CD}^{+} \mathrm{T}$ cells ignite acute gut GVHD}

Alloreactive $\mathrm{T}$ cell activation has been proposed to begin in the mesenteric lymph nodes (MLNs) and Peyer's patches $(13,14)$. Acute GVHD in the gut, the most common site of acute GVHD, results in a high mortality rate (15) and is primarily mediated by alloreactive $\mathrm{CD}^{+} \mathrm{T}$ cells. While transient in vivo depletion of donor $\mathrm{CD}^{+} \mathrm{T}$ cells effectively prevents the induction of acute gut GVHD (16), the subset of CD4 ${ }^{+} \mathrm{T}$ cells that initiates gut GVHD remains unclear. In this issue of the JCI, Ullich et al. have identified a subset of $\mathrm{CD} 4^{+} \mathrm{T}$ cells that initiates acute gut GVHD (17). These CD4 ${ }^{+} \mathrm{T}$ cells exhibited an effector memory (Tem) phenotype, with high levels of IL-7 receptor $\alpha(\mathrm{IL}-7 \mathrm{R} \alpha)$ expression and production of granulocyte-macrophage CSF (GM-CSF). These IL-7R $\alpha^{\text {hi }} \mathrm{GM}-\mathrm{CSF}^{+} \mathrm{CD} 4^{+}$Tem cells produced large amounts of IFN- $\gamma$, TNF- $\alpha$, and GM-CSF and little IL-17. Expression of IL-7R $\alpha$ was required for expansion of this subset, and production of GM-CSF was required for optimal pathogenicity. The generation of these $\mathrm{CD} 4^{+}$Tem cells was BATF dependent but ROR $\gamma$ t independent. The $\mathrm{CD}^{+}$Tem cells were augmented with IL-23 to produce GM-CSF, without production of IL-17.

Another subset of donor $\mathrm{CD}^{+}{ }^{+} \mathrm{T}$ cells with a central memory (Tcm) phenotype and expression of surface CD11c and IL-23R $\left(\mathrm{CD} 11 \mathrm{c}^{+} \mathrm{IL}-23 \mathrm{R}^{+} \mathrm{CD} 4^{+} \mathrm{Tcm}\right.$ cells) was recently identified by the Drobyski group as colitogenic $\mathrm{CD} 4^{+} \mathrm{Tcm}$ cells in acute GVHD recipients (18). CD11 $\mathrm{c}^{+}$ IL-23R $\mathrm{R}^{+} \mathrm{CD} 4^{+} \mathrm{Tcm}$ cells also produced large amounts of IFN- $\gamma$ and TNF- $\alpha$, with little IL-17. Although expression of IL-23R 


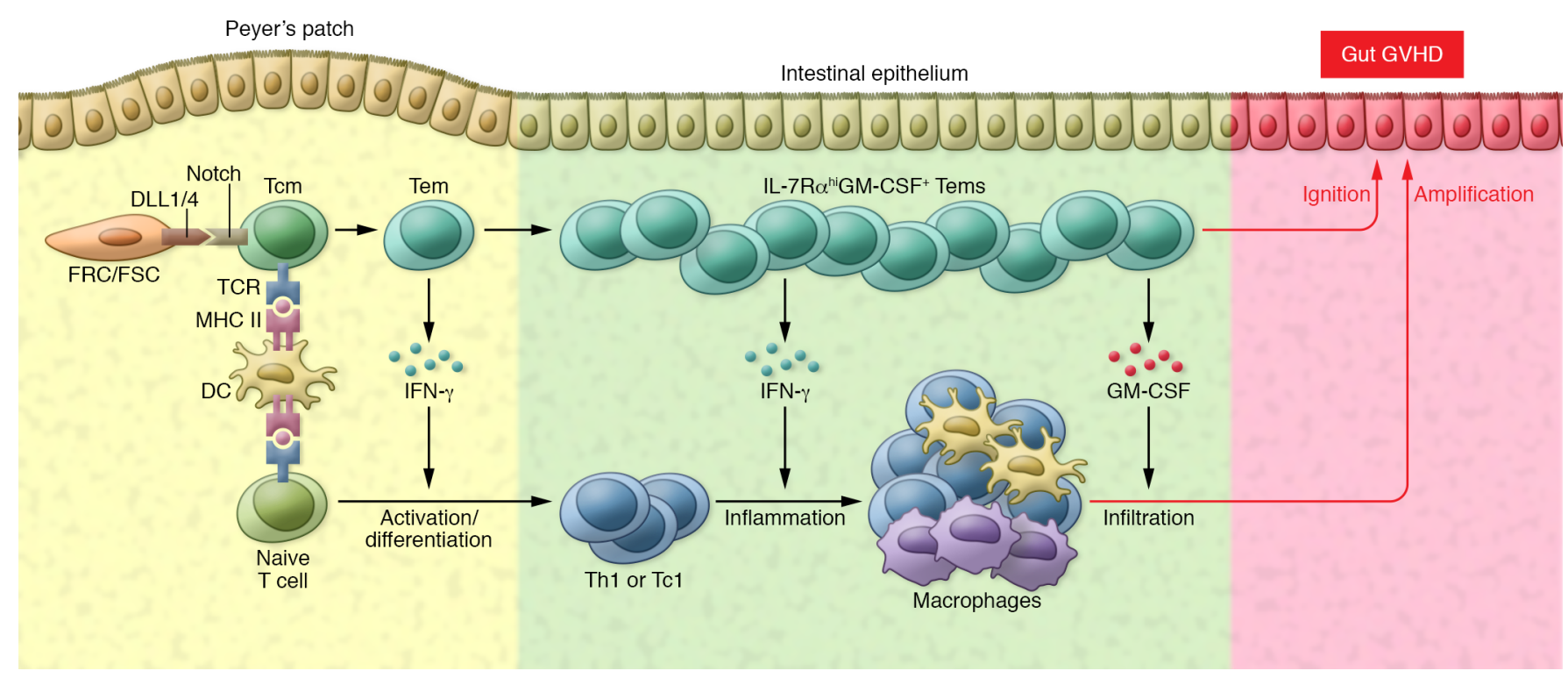

Figure 1. Diagram depicting the interactions of BATF-dependent, ROR $\gamma t$-independent Tem cells and Tem cells with host DCs, FSC/FRC, and donor naive T cells during development of acute gut GVHD. IFN- $\gamma$ from Tem cells augments naive T cell activation and differentiation into Th or Tc1 cells in the Peyer's patch. Tem cells produce GM-CSF to augment the infiltration of innate immune cells such as macrophages, while producing IFN- $\gamma$ to augment local inflammation. Tem cells ignite gut GVHD, and other cells amplify this GVHD. TCR, T cell receptor.

was required for $\mathrm{CD} 11 \mathrm{c}^{+} \mathrm{IL}-23 \mathrm{R}^{+} \mathrm{CD} 4^{+} \mathrm{Tcm}$ cell pathogenicity, IL-23 did not induce IL-17 production. This is consistent with the observation that IL-23 augmented IL-7R $\alpha^{\text {hi }} \mathrm{GM}-\mathrm{CSF}^{+} \mathrm{CD} 4^{+}$Tem cell production of GM-CSF in the absence of IL-17 (17), although it is not yet clear whether the $\mathrm{CD} 11 \mathrm{c}^{+} \mathrm{IL}-23 \mathrm{R}^{+} \mathrm{CD} 4^{+} \mathrm{Tcm}$ cells are also BATF dependent and ROR $\gamma t$ independent. Together, these observations indicate that the $\mathrm{CD}^{+} \mathrm{T}$ cells that initiate acute gut GVHD are IFN- $\gamma$-producing, Th1-like cells but not IL-17-producing Th17 cells. Interestingly, Fu et al. have reported that the prevention of acute gut GVHD requires T-bet deficiency in donor CD $4^{+} \mathrm{T}$ cells (19).

\section{Acute gut GVHD pathogenesis differs from chronic GVHD and autoimmune colitis}

BATF was found to be required for the differentiation of ROR $\gamma \mathrm{t}$-dependent Th17 cells that produced IL-17 and GM-CSF in a mouse model of experimental autoimmune encephalomyelitis (EAE), as well as in colitis-associated colon cancer $(6,20)$; however, the BATF-dependent IL-7R $\alpha^{\text {hi }}$

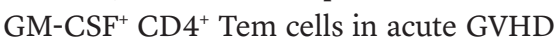
gut tissue were ROR $\gamma \mathrm{t}$ independent and did not produce IL-17, but instead produced IFN- $\gamma$, which is usually produced by T-betdependent Th1 cells (17). The mechanisms that regulate the differential generation of BATF-dependent, ROR $\gamma \mathrm{t}$-independent $\mathrm{CD}^{+}$Tem cells in acute gut GVHD as compared with BATF-dependent, ROR $\gamma$ tdependent Th17 cells in autoimmune EAE and colitis remain unclear, and these differences are likely conferred by the specific cytokine environment encountered. Acute GVHD is characterized by a cytokine storm with high concentrations of IFN- $\gamma$, TNF- $\alpha$, IL-1, and IL- 6 and low levels of TGF- $\beta$, a cytokine environment that favors Th1, but not Th17, differentiation (10). Moreover, IFN- $\gamma$ from Th1 cells can further inhibit this Th17 differentiation (8). As acute inflammation subsides and transitions into chronic inflammation, concentrations of IFN- $\gamma$ decrease, those of TGF- $\beta$ increase, and the cytokine environment gradually begins to favor Th17 differentiation (10). Thus, Th17 may participate in the pathogenesis at the early chronic GVHD phase. Although studies indicate that Th17 cells contribute to the pathogenesis of acute GVHD in mouse models and in humans $(21,22)$, kinetic analysis of gut tissue-infiltrating Th1 and Th17 cells has not been reported. Additionally, transplants from mice lacking ROR $\gamma \mathrm{t}$ (Roryt/-) do not prevent the induction of acute gut GVHD, despite a reduction in the severity of gut GVHD (23). Together, these observations indicate that Th17 cells are unlikely to initiate or play a critical role in acute gut GVHD.

\section{Perspectives}

Chung et al. recently reported that deltalike 1/4 (DLL1/4) ligand-mediated notch signaling is involved in the interaction between alloreactive $\mathrm{CD}^{+} \mathrm{T}$ cells and host fibroblast stromal cells (FSCs) and/ or fibroblast reticular cells (FRCs) in the lymph nodes and plays a critical role in priming the alloreactive $\mathrm{CD} 4^{+} \mathrm{T}$ cells within 48 hours of HCT (24). Thus, it is likely that interaction of the Notch receptor with its DLL1/4 ligands plays an important role in activating the memory $\mathrm{CD} 4^{+} \mathrm{T}$ cells that initiate gut GVHD.

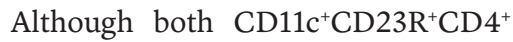
Tcm and IL-7R $\alpha{ }^{\text {hi GM-CSF }}{ }^{+} \mathrm{CD} 4^{+}$Tem cells initiate acute gut GVHD, the relationship between these subsets remains unclear. While depletion of naive $\mathrm{T}$ cells reduces chronic GVHD in both mouse models and humans, memory $\mathrm{T}$ cells are still able to induce acute gut GVHD (25). Therefore, it is possible that a subset of memory $\mathrm{CD} 4^{+}$ $\mathrm{T}$ cells can initiate gut GVHD, followed by amplification of the disease by activation and expansion of naive alloreactive $\mathrm{T}$ cells. Here, we propose a hypothesis that the memory $\mathrm{CD} 4^{+} \mathrm{T}$ cells ignite and promote acute gut GVHD development 
via interaction with host FSCs and FRCs, naive alloreactive $\mathrm{T}$ cells, and other innate immune cells.

Shortly after HCT, the CD11 $\mathrm{c}^{+} \mathrm{IL}-23 \mathrm{R}^{+}$ $\mathrm{CD}^{+}{ }^{+} \mathrm{Tcm}$ cells and naive alloreactive $\mathrm{T}$ cells migrate into MLNs and Peyer's patches (Figure 1). Here, the Tcm CD4 ${ }^{+} \mathrm{T}$ cells immediately interact with host DCs via their $\mathrm{T}$ cell receptor-MHC II binding and interact with host FSCs and FRCs via Notch receptors and DLL1/4 ligands. The reactivated Tcm cells rapidly develop into Tem cells that produce large amounts of IFN- $\gamma$ and other cytokines to augment naive alloreactive $\mathrm{T}$ cell activation and expansion. At the same time, Tem cells that express the gut-homing molecules $\alpha 4 \beta 7$ and CCR9 migrate into gut tissues and mediate local inflammation via production of GM-CSF and IFN- $\gamma$. The high-level of IL-7R $\alpha$ expression and production of IL- 2 make these Tem cells resistant to tissue programmed death ligand 1-mediated (PDL1-mediated) tolerance, as previously demonstrated (16). The production of GM-CSF and other cytokines and chemokines by Tem cells helps augment infiltration of innate immune cells and expansion of the alloreactive $\mathrm{T}$ cells derived from naive $\mathrm{T}$ cells, leading to fullblown gut GVHD. High concentrations of IFN- $\gamma$ and low concentrations of TGF- $\beta$ in the tissues during the early phase of acute gut GVHD can inhibit Th17 cell differentiation $(8,10)$. However, as acute inflammation transitions into the chronic phase, and as tissue concentrations of IFN- $\gamma$ decrease and those of TGF- $\beta$ increase, the effect of TGF- $\beta$, along with IL- 6 and IL-1, leads to Th17 cell differentiation. Therefore, BATF-dependent, ROR $\gamma$ t-independent Th1-like $\mathrm{CD}^{+} \mathrm{T}$ cells initiate acute gut GVHD development, and RORt-dependent Th17 cells may participate in the early stage of chronic GVHD.

Future studies are warranted to test this hypothesis. In particular, several questions need to be answered. First, can CD11c ${ }^{+} \mathrm{IL}-23 \mathrm{R}^{+} \mathrm{CD} 4^{+} \mathrm{Tcm}$ cells give rise to the BATF-dependent, ROR $\gamma$ t-independent IL-7R $\alpha^{\text {hi }} \mathrm{GM}-\mathrm{CSF}^{+}$Tem cells, and are these cells T-bet dependent? Second, how do Tcm cells interact with FSCs and FRCs in MLNs and Peyer's patches? Finally, as dysbiosis plays an important role in augmenting acute gut GVHD (26), how does the intestinal microbiota influence the activation and expansion of Tcm cells, or vice versa?

In summary, BATF-dependent, ROR $\gamma \mathrm{t}$ independent $\mathrm{IL}^{-7 R} \alpha^{\text {hi GM-CSF}}{ }^{+}$Tem cells play a critical role in initiating acute gut GVHD pathogenesis, and targeting the IL-7R/BATF/GM-CSF axis has therapeutic potential for treating acute gut GVHD.

\section{Acknowledgments}

The author's research is supported by a grant from the National Institute of Allergy and Infectious Diseases (NIAID), NIH (R01 AI 066008). The author thanks his lab members Qingxiao Song and Kaniel Cassady for their help: Qingxiao for making the artful diagram of Figure 1, and Qingxiao and Kaniel Cassady for their critical review of this Commentary.

Address correspondence to: Defu Zeng, The Beckman Research Institute of City of Hope, 1500 East Duarte Road, Duarte, California 91010, USA. Phone: 626.218.3587; Email: dzeng@coh.org.

1. Cutler C, Antin JH. Manifestations and treatment of acute graft-versus-host disease. In: Appelbaum FR, Forman SJ, Negrin RS, Blume KG, eds. Thomas' Hematopoietic Cell Transplantation. Oxford, United Kingdom: Wiley-Blackwell; 2009:1287-1303.

2. Chakraverty R, et al. An inflammatory checkpoint regulates recruitment of graft-versus-host reactive T cells to peripheral tissues. J Exp Med. 2006;203(8):2021-2031.

3. $\mathrm{Wu} \mathrm{T}$, et al. Thymic damage, impaired negative selection, and development of chronic graftversus-host disease caused by donor $\mathrm{CD}^{+}$and CD8+ T cells. J Immunol. 2013;191(1):488-499.

4. Zhang Y, Hexner E, Frank D, Emerson SG. CD4 $\mathrm{T}$ cells generated de novo from donor hemopoietic stem cells mediate the evolution from acute to chronic graft-versus-host disease. JImmunol. 2007;179(5):3305-3314.

5. Zhu J, Yamane H, Paul WE. Differentiation of effector CD4 T cell populations (*). Annu Rev Immunol. 2010;28:445-489.

6. Schraml BU, et al. The AP-1 transcription factor Batf controls T(H)17 differentiation. Nature. 2009;460(7253):405-409.

7. DuPage M, Bluestone JA. Harnessing the plasticity of CD4(+) T cells to treat immune-mediated disease. Nat Rev Immunol. 2016;16(3):149-163.

8. Yi T, et al. Reciprocal differentiation and tissuespecific pathogenesis of Th1, Th2, and Th17 cells in graft-versus-host disease. Blood. 2009;114(14):3101-3112.

9. Yi T, et al. Absence of donor Th17 leads to augmented Th1 differentiation and exacerbated acute graft-versus-host disease. Blood. 2008;112(5):2101-2110.

10. Henden AS, Hill GR. Cytokines in graft-versushost disease. JImmunol. 2015;194(10):4604-4612.

11. Jin $\mathrm{H}$, et al. Antibodies from donor B cells perpetuate cutaneous chronic graft-versus-host disease in mice. Blood. 2016;127(18):2249-2260.

12. Gartlan $\mathrm{KH}$, et al. A critical role for donorderived IL-22 in cutaneous chronic GVHD [published online ahead of print September 23, 2017]. Am J Transplant. https://doi.org/ 10.1111/ajt.14513.

13. Murai M, et al. Peyer's patch is the essential site in initiating murine acute and lethal graft-versushost reaction. Nat Immunol. 2003;4(2):154-160.

14. Beilhack A, et al. Prevention of acute graftversus-host disease by blocking T-cell entry to secondary lymphoid organs. Blood. 2008;111(5):2919-2928.

15. Naymagon S, et al. Acute graft-versus-host disease of the gut: considerations for the gastroenterologist. Nat Rev Gastroenterol Hepatol. 2017;14(12):711-726.

16. Ni X, et al. PD-L1 interacts with CD80 to regulate graft-versus-leukemia activity of donor $\mathrm{CD}^{+} \mathrm{T}$ cells. J Clin Invest. 2017;127(5):1960-1977.

17. Ullrich E, et al. BATF-dependent IL-7R ${ }^{\text {hi }} \mathrm{GM}-\mathrm{CSF}^{+}$ $\mathrm{T}$ cells control intestinal graft-versus-host disease. JClin Invest. 2018;128(3):916-930.

18. Zhou V, et al. A colitogenic memory $\mathrm{CD}^{+}{ }^{+} \mathrm{T}$ cell population mediates gastrointestinal graft-versushost disease. JClin Invest. 2016;126(9):3541-3555.

19. Fu J, et al. T-bet is critical for the development of acute graft-versus-host disease through controlling $\mathrm{T}$ cell differentiation and function. J Immunol. 2015;194(1):388-397.

20. Punkenburg E, et al. Batf-dependent Th17 cells critically regulate IL-23 driven colitis-associated colon cancer. Gut. 2016;65(7):1139-1150.

21. Kappel LW, et al. IL-17 contributes to CD4mediated graft-versus-host disease. Blood. 2009;113(4):945-952.

22. Bossard C, et al. Plasmacytoid dendritic cells and Th17 immune response contribution in gastrointestinal acute graft-versus-host disease. Leukemia. 2012;26(7):1471-1474.

23. Fulton LM, et al. Attenuation of acute graft-versushost disease in the absence of the transcription factor ROR $\gamma$ t. JImmunol. 2012;189(4):1765-1772.

24. Chung J, et al. Fibroblastic niches prime T cell alloimmunity through $\Delta$-like Notch ligands. J Clin Invest. 2017;127(4):1574-1588.

25. Bleakley M, et al. Outcomes of acute leukemia patients transplanted with naive $\mathrm{T}$ cell-depleted stem cell grafts. J Clin Invest. 2015;125(7):2677-2689.

26. Shono Y, et al. Increased GVHD-related mortality with broad-spectrum antibiotic use after allogeneic hematopoietic stem cell transplantation in human patients and mice. Sci Transl Med. 2016;8(339):339ra71. 